\title{
HOMBRES DE COLOR E OS SIGNIFICADOS DA LIBERDADE NEGRA: CONTRIBUIÇÕES À HISTÓRIA DO PÓS-ABOLIÇÃO NO URUGUAI (1872)
}

Hombres de Color and the Meanings of Black Freedom:

Contributions to the History of Post-Abolition in Uruguay (1872)

Hombres de color y los significados de la libertad negra:

contribuciones a la historia de la post-abolición en Uruguay (1872)

FERNANDA OLIVEIRA ${ }^{I^{*}}$

DOl:http://dx.doi.org/10.1590/S2178-149420190001000010

\footnotetext{
${ }^{\mathrm{I}}$ Universidade Federal de Pelotas (UFPel), Pelotas - RS, Brasil.

*Professora substituta do Curso de História da Universidade Federal de Pelotas. Estágio pós-doutoral pela UFRRJ, coordenadora da Setorial Sul do GT Emancipações e Pós-Abolição da ANPUH. (feolisilva@gmail.com),

ORCID iD: https://orcid.org/0000-0001-8198-3552
}

Artigo recebido em 15 de novembro de 2018 e aceito para publicação em 12 de fevereiro de 2019. 


\section{RESUMO}

A conformação do Estado republicano uruguaio e sua relação com a libertação dos escravizados é assunto recorrente nos estudos históricos. Com o intuito de contribuir para esse debate, alargando-o a partir de apontamentos sobre as condições do pós-abolição, apresento este artigo adotando por fio condutor um acontecimento de 1872: a criação do Club Igualdad. Composto por um grupo de homens de color em um contexto de disputas eleitorais, a justificativa para a sua criação estava na denúncia de que a ideia de raça apresentava uma intrínseca relação com 0 acesso à cidadania naquela capital emancipada desde a década de 1840 .

PALAVRAS-CHAVE: Uruguai; Liberdade; Pós-abolição; Negros; Branquitude; República.

\section{ABSTRACT}

The conformation of the Uruguayan republican State and its relationship with the liberation of the enslaved is a recurrent subject in historical studies. In order to contribute to this debate, extending it based on notes on the conditions of post-abolition, I present this article taking as guideline an event of the year 1872: the creation of Club Igualdad. Composed of a group of men of color in a context of electoral disputes, the justification for its creation resided in the denunciation that the idea of race had an intrinsic relationship with the access to the citizenship in that emancipated capital ever since the 1840s.

KeYwORDS: Uruguay; Freedom; Post-abolition; Blacks; Whiteness; Republic.

\section{RESUMEN}

La conformación del Estado republicano uruguayo y su relación con la liberación de los esclavizados es asunto recurrente en los estudios históricos. Con el fin de contribuir a ese debate, ampliándolo a partir de apuntes sobre las condiciones de la post-abolición, presento este artículo tomando por hilo conductor un acontecimiento del año 1872: la creación del Club Igualdad. Compuesto por un grupo de hombres de color en un contexto de disputas electorales, la justificación para su creación estaba en la denuncia de que la idea de raza presentaba una intrínseca relación con el acceso a la ciudadanía en aquella capital emancipada desde la década de 1840.

PALABRAS CLAVE: Uruguay; Libertad; Post-abolición; Negros; Blancura; Republica. 


\section{DILEMAS INSTITUCIONAIS DA LIBERDADE NEGRA}

L evar à "Representación Nacional un hombre de nuestra clase" era a reivindicação do candidato do Club Igualdad, o militar de color José María Rodriguez. Por clase leia-se coletivo de pessoas que compartilhavam um mesmo objetivo: o fim dos recrutamentos forçados de homens negros instituídos pelas leis de abolição, como veremos em seguida. 0 clube foi fundado em 25 de agosto de 1872 por Eulogio Alsina, José María Rodriguez, Timoteo Olivera, Manuel Aturaola, Manuel Gutiérrez e, possivelmente, outros homens negros, e teve como porta-voz o jornal La Conservación, principal fonte utilizada nesse artigo. ${ }^{1}$

As demandas do Club Igualdad adquirem sentido ao observarmos os dilemas da história da população negra naquela nação, sem perder de vista a realidade das Américas. As duas leis de abolição da escravidão uruguaia foram promulgadas no contexto da Guerra Grande (1839-1851) e estavam relacionadas aos interesses de ambos os lados envolvidos no conflito. ${ }^{2}$ A primeira delas foi promulgada em 1842 pelo governo colorado, comandado por Fructuoso Rivera, com sede em Montevidéu, sob apoio dos unitários argentinos, da França e da Inglaterra. ${ }^{3}$ A lei institucionalizava a obrigatoriedade do serviço militar aos homens negros pelo tempo que fosse necessário, e informava que mulheres, crianças e homens não aptos à função de soldados ficariam prestando serviço aos seus antigos senhores, na modalidade de regime de patronato, com o estabelecimento dos contratos de peonagem. Alerto que, se os homens negros eram quase-cidadãos, ${ }^{4}$ ou seja, não mais escravizados, mas tampouco cidadãos com direito a liberdade incondicional, ${ }^{5}$ a mesma coisa não valia para as mulheres e as crianças, pois estas seguiam sob jugo do mesmo senhor, e sequer anteviam uma data para o acesso ao direito de ir e vir. ${ }^{6}$

Os contratos de trabalho não foram uma especificidade uruguaia no processo de emancipação da escravidão, e, assim como a maioria dos demais espaços americanos, excluindo-se apenas o Brasil, o significado desse processo estava diretamente vinculado com o contexto histórico das guerras de independência, no qual se encontra a Guerra Grande (Cooper; Holt; Scott, 2005: 89-129; Andrews, 2007: 83-150). É importante destacar que o governo radicado em Montevidéu, denominado Gobierno de la Defensa, assinou um acordo para o fim do tráfico de escravos com a Inglaterra no ano inicial do conflito (1839), e a influência é marcante na redação da lei de abolição, que advém da ratificação do referido acordo: "Que en ningún caso es más urgente el reconocimiento de los derechos que estos individuos tienen de la naturaleza, la Constitución y la opinión ilustrada de nuestro siglo". Em seguida, afirma "que en las actuales circunstancias en que la República necesita de hombres libres, que defiendan las libertades y la independencia de la Nación".7 A redação da referida lei é bastante 
ilustrativa dos ideários e do contexto específico. Conforme se pode observar no referente às condições da liberdade dos escravizados:

Artículo $1^{\circ}$. - Desde la promulgación de la presente resolución, no hay esclavos en todo el territorio de la República.

$2^{\circ}$. - El Gobierno destinará los varones útiles que han sido esclavos, colonos o pupilos, cualquiera que sea su denominación, al servicio de las armas por el tiempo que crea necesario.

$3^{\circ}$. - Los que no sean útiles para el servicio militar, y las mujeres, se conservarán en clase de pupilos al servicio de sus amos, con sujeción por ahora a la ley patria sobre pupilos o colonos africanos.

$4^{\circ}$. - Los derechos que se consideren perjudicados por la presente resolución serán indemnizados por leyes posteriores.

Comuníquese al P. E., etc.

Sala de Sesiones en Montevideo, a 12 de diciembre de 1842.

\section{Manuel B. Bustamante.}

Juan A. la Bandera. (Grifos do original.) ${ }^{8}$

Estas condições reforçam elementos que já haviam figurado antes, e, entre estes estavam os colonos e pupilos, ou qualquer que fosse sua denominação, uma referência explícita aos hombres de color referenciados na Assembleia Geral de $1837 .{ }^{9} \mathrm{~A}$ referência racializada substituía uma menção ao estatuto jurídico e/ou ao trabalho que desempenhavam, como escravos, colonos ou pupilos. Enfatizava o traço compartilhado por todos - de color -, e afirmava que todos seriam considerados livres, sendo que os menores de 25 anos deveriam servir os seus senhores, agora denominados patrões, por um período de três anos, pelo regime de patronato, independendo de serem livres ou escravizados antes da promulgação da lei. Além de configurar uma franca aparição da forma como a racialização ${ }^{10}$ de homens - e talvez mulheres - negros se deu na formulação de leis no território oriental, apresenta também uma restrição de cidadania ao ampliar o controle sobre os significados da liberdade para os homens negros livres, sobretudo no que tange ao cerceamento de escolha de trabalho. Um efeito prático da lei foi o cerceamento da liberdade por meio da manutenção do patronato, o qual só seria extinto no início da década de 1860.

Em um intervalo de quatro anos, a lei promulgada pelo governo radicado em Montevidéu foi seguida pela promulgação de lei semelhante, em 26 de outubro de 1846, por parte 
do governo radicado no interior. Sob as diretrizes dos blancos liderados por Manoel Oribe e Bernardo Berro, essa lei, em seu artigo 10, informa que "Queda abolida para siempre la esclavitud en la República". Em seguida, "se establece que, desde la promulgación de esa ley 'entran al goce de su libertad todos aquellos esclavos que no hayan sido emancipados de derecho'" (Borucki, Chagas, Stalla, 2009: 70). ${ }^{11}$ Um efeito da lei foi o fortalecimento das fileiras dos exércitos, visto que por meio das solicitações de indenização pelos senhores, o governo pôde contabilizar e certificar-se das condições dos escravizados com vistas ao recrutamento, 0 que de fato se deu em seguida (Menegat, 2015).

A lei de abolição do ano de 1842 permite observar a racialização e, ainda, a questão do patronato/custódia/pupilagem, que aponta para a ideia de aprendizado da liberdade. Estes termos foram desenvolvidos por Thomas Holt como forma de caracterizar a justificativa acionada na concessão restrita de liberdade pelo programa britânico de emancipação na Jamaica entre 1833 e 1866 (Cooper, Holt, Scott, 2005: 89-129). As discussões legislativas sobre a restrição da liberdade no território uruguaio permitem acompanhar a ênfase no controle, sob a justificativa de uma possível desordem frente à (suposta) não experiência dos antigos escravizados com a liberdade, assim como a propensão à vadiagem, prostituição e crimes de toda a ordem (Borucki, Chagas, Stalla, 2009). ${ }^{12}$

Nesse sentido, interpreto que os contratos compõem um importante significado da pedagogia adotada pelo governo uruguaio para ensinar os trâmites da liberdade, notadamente limitada e mantenedora de lugares sociais estabelecidos durante a vigência da escravidão. 0 governo tinha como objetivo a manutenção de mão de obra e população, bem como a defesa da nação, de forma a ter uma população que justificasse e assegurasse a soberania nacional. Ressalto que se trata de população e não de cidadãos com poder de decidir o futuro político da nação, visto que a Constituição de 1830, embora considerasse que ninguém mais nasceria escravo, ou seja, o ventre passava a ser livre, suspendia a cidadania aos soldados de línea, por exemplo. Logo, a restrição de cidadania aos homens negros com menos de 25 anos e a obrigatoriedade de ser soldado legalizavam a relação entre coerção sobre a força de trabalho livre e direitos políticos em tempos de liberdade. Não esquecendo que a coerção sobre a força de trabalho livre, mediante os contratos de peonagem, alcançou também as mulheres negras livres, homens negros considerados inaptos. e menores negros. 0 fim formal dessa prática em relação aos menores negros se deu em 2 de maio de 1853, enquanto que os demais foram atingidos apenas em 2 de julho de 1862, com a declaração de nulidade dos contratos de peonagem pelo então presidente Bernardo Berro (Borucki, Chagas, Stalla, 2009: 96, 147).

Destaco ainda o elemento censitário, a política de incentivo à imigração europeia, e a relação de ambos com o conteúdo das demandas do Club Igualdad. 0 último Censo Nacional 
uruguaio do século XIX, que contabilizou em separado negros e brancos, além de mulatos, mestiços e indígenas, data de 1852, enquanto que o último Censo Municipal (para Montevidéu) data de 1884. Em 1852, de um total de 131.969 habitantes, as categorias "negros" e "mulatos" representavam 8.8\%, frente a $64.1 \%$ de brancos; em 1884, na cidade de Montevidéu foi contabilizada uma população de 214.951 habitantes, sendo $0.9 \%$ negros e mulatos e $98.8 \%$ brancos (Andrews, 2011: 23). A primeira lei geral que regulou e previu incentivos à imigração no país data de 1890. No entanto, a Ley n 320, de 1853, direcionada à agricultura, já explicitava benefícios aos colonos europeus que se estabelecessem em colônias agrárias, denominados colonos inmigrantes (Arocena; Aguiar, 2007: 47), denominação esta que também foi racializada: vale lembrar que o $2^{\circ}$ artigo da Lei da Abolição, de 1842, mencionava os colonos, leia-se os hombres de color. As leis mostram que, enquanto as pessoas negras tinham sua liberdade condicionada e, consequentemente, sua cidadania limitada, os europeus eram bem-vindos no Estado Oriental e beneficiados com incentivos. Os dados dos censos de 1852 e 1884 certamente precisam ser problematizados, e possivelmente não correspondem à realidade (Andrews, 2011), mas, somados ao contexto de chegada dos imigrantes europeus, são um indício de que população e cidadãos eram considerados importantes para as autoridades da jovem nação, assim como são um indício do significado de clase na demanda do Club Igualdad, explicitado no jornal La Conservación. Feito o preâmbulo acerca das leis de emancipação e da forma como a racialização se fez presente, é momento de voltarmos ao Club lgualdad e à sociedad de color.

\section{A SOCIEDAD DE COLOR E OS IDEAIS REPUBLICANOS}

O primeiro número do jornal La Conservación - Órgano de la Sociedad de Color, que circulou nas ruas de Montevidéu a partir do dia 4 de agosto de 1872,13 trazia no editorial cuja redação estava a cargo de Marcos Padín, Augustin Garcia e Andrés Seco - a justificativa para a sua criação: "Nosotros nos presentamos defendiendo un derecho justo, un derecho de principios, un derecho sagrado". ${ }^{14}$ Após pouco mais de um mês, o jornal que circulou no dia 15 de setembro de 1872 informava também no editorial que "La Conservación es un órgano de la sociedad de color, es un periódico sin color político, que viene a la prensa a defender nuestros derechos". 15

Corria a campanha eleitoral para a asamblea general, ${ }^{16}$ a se realizar no último domingo de novembro daquele ano, e a experiência de formar clubes de caráter político fazia parte de um repertório cultural disponível, ou minimamente conhecido pelos moradores e moradoras 
da capital uruguaia. A década de 1870 foi marcada por uma profusão de clubes vinculados à política institucional na capital uruguaia, todos buscando alcançar adeptos, fosse por meio de antigas cores que nomeavam os dois principais partidos, o Blanco e o Colorado, ou com novos nomes na cena política. Ao abordar a experiência negra no Uruguai, o historiador George Andrews (2011) fala da existência de um furor clubista que caracterizava Montevidéu na segunda metade do século XIX. No entanto, essa não foi uma experiência condicionada ao Uruguai, tampouco às Américas. 0 historiador Peter Burke (2002), em um texto jornalístico intitulado História social dos clubes, lança alguns elementos que auxiliam na compreensão da cultura de clubes. 0 veículo de divulgação do referido texto em parte corrobora a popularidade da experiência clubista, a qual, nas palavras do autor, surgiu no século XIV, no mundo de fala inglesa. 0 auge foi nos séculos XVIII e XIX em uma intrincada relação com as ideias de modernidade, democracia, iluminismo e urbanização que, por sua vez, foram vivenciadas nos clubes. Tais colocações permitem que tenhamos noção de que o social a que o autor se refere é o europeu; no entanto, ele não se exime de apresentar exemplos fora deste centro, com ênfase para as sociedades asiáticas e africanas e um pequeno exemplo nas Américas, mais precisamente nos Estados Unidos da América.

Dois elementos principais do texto de Burke auxiliam na construção do argumento deste artigo: associação e democracia. 0 autor identifica a formação dos clubes como parte de uma longa experiência de criação de associações voluntárias. Estas tiveram/têm suas expressões em diferentes partes do mundo, como, por exemplo, os clubes de interesses especiais, de integração de imigrantes, políticos (séc. XVII), de esporte (séc. XVIII), étnicos (séc. XVII) e tribais. Argumento que é na organização e no fazer-se dos clubes que reside a possibilidade de vivenciar aquilo que identifico por aprendizagem da democracia e consolidação de uma cidadania, na esteira de Cooper, Holt e Scott (2005) em relação à liberdade. Fortaleço o argumento destacando a perspectiva do associado de um clube americano do século XVIII reproduzida por Peter Burke (2002): "os clubes eram 'governos em miniatura' ou pequenos 'Parlamentos', oferecendo um treinamento em cultura democrática, em liberdade, igualdade e, sobretudo em fraternidade".

Sobre os clubes no século XIX, Burke destaca o papel de mediação que desempenhavam entre aquilo que era de cunho privado (âmbito da família) e público (âmbito do Estado), o que, por sua vez, nos permite remontar às sociedades civis reivindicadas pelo intelectual negro uruguaio Jacinto Ventura de Molina. Para Molina, os homens - de forma universal - construíram, ao longo da história, uma gama de corporações, denominadas sociedades civiles, por meio das quais podiam assegurar a "libertad, seguridad de sus propiedades, librándose de la violencia de los extranjeros". ${ }^{17}$ 
É o conteúdo de uma parte da sociedade civil, a denominada sociedad de color, que acompanhamos por meio da experiência do Club Igualdad, criado no ano das eleições para o Parlamento Nacional. 0 clube tinha como presidente um de seus fundadores, José María Rodríguez, militar negro que alcançou o posto de major e era secretariado por Luis Gonzalez, também negro. 0 jornal era editado em Montevidéu, e circulou semanalmente (aos domingos) entre os dias 4 de agosto e 24 de novembro de 1872.

Nas matérias do jornal, encontramos a defesa do direito à igualdade, civil e política, que, por sua vez, dava nome ao clube. Essa igualdade era entendida como negada à raza negra pelos preconceitos arraigados no simples fato de terem os indivíduos a ela pertencente a faz de color oscura. De forma filtrada, referia-se às señoritas, mas o conteúdo do jornal era majoritariamente direcionado ao público masculino. Considerando o objetivo político institucional do clube, é de se entender que as mulheres figurem pouco, afinal, elas não tinham direito ao voto. É importante observar que essa questão não foi problematizada, permitindo interpretar uma sociedad de color de significado supostamente universal, mas concretamente entendida como masculina.

O clube pleiteou a construção de uma pauta política compartilhada com a/na sociedad de color, consolidando um nome que o representasse nas eleições. Este nome foi apresentado na edição de 29 de setembro de 1872, e tratava-se do presidente do clube, "El señor Rodríguez, hombre ilustrado e intrépido, para desempeñar ese puesto, ó mas bien dicho para representar nuestra raza". ${ }^{18}$ Afinal, alertavam os então redatores Marcos Padín e Andres Seco: "¿Quién mejor que el señor Rodríguez puede dignificar una raza, que marcha hoy á pasos agigantados hacia la senda del progreso de la ilustración?". ${ }^{19}$ Ainda nas palavras dos redatores está o que para mim é a síntese desse projeto e do seu contexto histórico:

La base de las sublimes instituciones democráticas es, a no dudarlo, la libertad.

La base que sirve para formar un buen ciudadano es la práctica de esa libertad.

No es hombre libre, ni ciudadano, el que no practique los sagrados derechos que la libertad le confía.

No hay hombre más libre que aquel que está dispuesto a sacrificarse por sus derechos.

En este sentido; ciudadanos de nuestra raza, qué más podemos deciros, sino que la práctica de la libertad bien entendida es el culto que debemos a la sublime religión de la patria.

Esa práctica consiste, principalmente, en depositar, en las Urnas Electorales, nuestro voto por el hombre que nos parece más apto para representarnos en el Parlamento Nacional; voto nacido de nuestra libre y espontánea libertad. ${ }^{20}$ 
0 clube foi criado dez anos após o fim da legalidade dos contratos de peonagem. Mas ainda vigoravam os recrutamentos forçados de homens negros, algo que só seria abolido em 1876 pelo governante ditatorial, Lorenzo Latorre. De acordo com o jornal, os negros eram vistos por muitos como carne de cañón, ${ }_{1}^{21}$ ou seja, como disponíveis e obrigados a aceitar o recrutamento. Na citação anterior, cujo conteúdo foi retomado em todos os números posteriores disponíveis para pesquisa, estão presentes noções universais próprias de instituições democráticas modernas, como liberdade, cidadania política e direito ao voto. Essas noções foram reivindicadas dentro da sociedade uruguaia, e, especialmente, frente à instituição política, 0 Parlamento Nacional, no qual os adeptos do clube não se viam representados e respeitados em seu direito de igualdade, algo que deveria ser inerente à liberdade em se tratando de instituições democráticas. A falta de igualdade era entendida como diretamente ligada ao passado escravista, com a manutenção de lugares sociais próprios do passado e a consequente exclusão que se colocou lado a lado da abolição e reverberou na instituição de representação política, cerceando o significado de liberdade.

Percebo um traço do que Frederick Cooper, Thomas Holt e Rebecca Scott (2005) identificaram como problemas da liberdade, ${ }^{22}$ e do que W. E. B. Du Bois, em seu estudo sobre a sociedade norte-americana no pós-emancipação, rotulou como democracia da abolição, que, na interpretação de Angela Davis (2009: 86-87):

Significa falar não unicamente, e nem fundamentalmente, sobre a abolição como um processo negativo de demolição, mas também como um processo de construção, de criação de novas instituições. [...] Du Bois salientou que, para abolir completamente as condições opressivas produzidas pela escravidão, novas instituições democráticas teriam de ser criadas. Por isso não ter ocorrido, os negros encontraram novas formas de escravidão.

A partir da edição em que foi abertamente contestada a igualdade com base em uma ideia de raça que inferiorizava os negros daquela capital, e daquele país, se acessa uma repercussão pouco favorável às denúncias e afirmações feitas nas páginas do jornal. Observa-se tanto o rechaço de outros órgãos da imprensa montevideana ${ }^{23}$ frente à divulgação de que a demanda por igualdade era explicitamente racializada, em virtude da não ação de homens brancos em prol de homens negros, quanto a não aceitação dos mesmos ideais por membros de outro clube negro, o Club Defensa, ${ }^{24}$ cujos vínculos políticos eram com o Partido Colorado. São essas discussões que acompanharemos em seguida. 


\section{A BRANQUITUDE TAMBÉM FAZ PARTE DA RACIALIZAÇÃO}

percepção, que coloca em evidência a ação de homens brancos, foi acionada algumas
vezes nas páginas do La Conservación. Transcrevo a seguir uma reportagem bastante peculiar, e que, embora longa, é aqui utilizada como síntese das discussões feitas na emancipada, mas não tão democrática, Montevidéu:

Los hombres blancos serán siempre los mismos, por más que ellos quieran disimular su despego, a nuestra raza aparentando sentimientos liberales, y democráticos.

La prueba la estamos viendo con lo que sucede hoy, al Club Defensa, $q^{\prime}$ creyendo de que con ser fiel al partido por el cual tanta sangre derramaron los hombres de color, en todas las luchas que dicho partido á sostenido y sostiene, desde mucho tiempo, y sobre todo, en la inmortal defensa de la nueva Troya, en que nuestra raza, con un valor a toda prueba hicieron prodigios que son unas de las páginas más gloriosas; de nuestra historia.

¡Creyeron, repito; que ese partido no sería ingrato y que hoy que nuestra raza reclaman como premio a sus servicios, el más sagrado, de los derechos del hombre, q' es el derecho de igualdad; hoy esos hombres temen hacharse con tener como a sus iguales a los hombres de color!

Fatal; contraste.

El Imperio del Brasil, donde reina la aristocracia; y la esclavitud, seden a los hombres de color, el derecho de igualdad.

La gran Confederación argentina admite en su representación a los hombres de color.

Pero la República del Uruguay no puede admitir en su Representación a los hombres de color.

¿Por qué será esto, serán los hombres de color ciudadanos legales de la República o no?

Creo que sí, una vez que cuando la Patria está en los mayores peligros llaman en su defensa a todos sus hijos sin distinción de color.

$[\ldots]$

Por qué los hombres de color han conocido que en esta República, los hombres blancos, sea cual sea la opinión á que pertenezcan, son enemigos de nuestra raza. ${ }^{25}$

Tais afirmativas, comuns nas edições do jornal, permitem interpretar uma leitura complexa da exclusão com base na ideia de raça, em que, de um lado, estão os excluídos, no caso, os negros, e de outro, os beneficiados, os brancos. A interpretação acerca dos hombres blancos permite a aproximação da noção de branquitude, que, nas palavras do cientista social Lourenço Cardoso (2014: 17), é a "pertença étnico-racial atribuída ao branco", sendo que "ser 
branco consiste em ser proprietário de privilégios raciais simbólicos e materiais. Ser branco significa mais do que ocupar os espaços de poder. Significa a própria geografia existencial do poder". A esta compreensão alio a de Frederick Cooper, Thomas Holt e Rebecca Scott (2005: 58) em relação à noção de liberdade e cidadania em meados do século XIX:

[... a liberdade, para a maioria dos brancos de ambos os lados do mundo atlântico, envolvia pertencer a um corpo político. Pertencia-se a uma comunidade como cidadão e através da cidadania; os cidadãos, como um coletivo, constituíam e, em teoria, governavam a sociedade da qual faziam parte. Com esta mudança [emancipação dos escravos], e sem importar até que ponto pode ter sido real na prática, os problemas da manumissão e da emancipação foram redefinidos. À questão de como os escravos se tornariam livres acrescentou-se o problema do que provocaria sua nova relação com a sociedade como um todo. Seriam eles também cidadãos?

A demanda do clube foi justificada em bases sociais a partir da importância da população negra. A transcrição está repleta de elementos históricos, e evidencia compreensões como a defesa da capital durante a Guerra Grande, evocada como nuestra Troya ${ }^{26}$ as experiências de hombres de color nas nações vizinhas, incluindo o Brasil, o sentido de cidadania como igualdade, e o caráter não igualitário denunciado na República do Uruguai, sendo que república e hombres blancos são tomados como sinônimos (aqui há ainda uma ironia em relação às cores dos partidos), e finaliza colocando a discussão em termos explicitamente racializados, ao enfatizar os enemigos de nuestra raza.

A discussão foi intensa acerca das considerações sobre os homens brancos e, consequentemente, sobre o que interpreto como forma de reagir a uma racialização que se impunha aos negros da capital oriental, dentro da qual eles dialogaram e também consolidaram suas formas de ver o mundo e reivindicar transformações sociais condizentes com a abolição da escravidão e a efetivação da cidadania. Embora não tenha me dedicado ao exame de outras fontes periódicas, algo que foge ao foco desta pesquisa, as análises a que tive acesso sobre esse momento histórico apontam para uma repercussão acentuada; logo, é possível que a demanda tenha provocado atenção e incômodo (Goldman, 2016; 2015).

Os redatores do La Conservacíon destacaram que a cidadania, entendida como um fazer parte do corpo político, estava cerceada, calcada em uma diferença de cores que sustentava a ideia de raça, branca e de color, mesmo que fossem eles ciudadanos libres. Essa situação só seria revertida quando um homem negro comprometido com as questões da sociedad de color ocupasse uma cadeira na Representación Nacional.

Amparado na análise de outros jornais que circularam na cidade de Montevidéu no ano de 1872, Gustavo Goldman informa que os membros de ambos os clubes negros, Igualdad e 
Defensa, uniram-se em torno da indicação do nome do senhor Rodríguez, sócio de ambos os clubes. Pleitearam que este nome estivesse incluso na lista do Partido Colorado. Quando este partido aparentemente declinou da indicação, os membros do Club Igualdad passaram a exigir que o Club Defensa abandonasse o referido partido e os apoiasse em torno do nome (ibidem, 2016).

Até o último número disponível para a pesquisa, que data de 24 de novembro de 1872, a capa e parte da página 2 estão repletas de posicionamentos sobre a desunião da sociedad de color, com seus hombres de color e las morochas, ${ }^{27}$ cujo traço comum era a cor da pele e os antepassados escravizados e/ou carnes de cañón. Aqui estão alguns elementos que permitem acessar tanto as divergências de estratégias políticas entre os grupos negros quanto a racialização que se fazia em tempos de pós-abolição, em uma sociedade tida como democrática e exemplar em termos de direitos civis e políticos quando se trata das Américas.

Na esteira de Paul Gilroy (2001: 234) sobre a interpretação da cultura dos negros na diáspora, devidamente informado por W. E. B Du Bois, a análise do periódico La Conservación permite explicar um fazer-se da raça que inclui, a partir da consciência de se ver como negro e uruguaio, sem que tais identidades sejam conflituosas, mas simultâneas: uma fundamenta e fortalece a outra no sujeito que a vive. Aparentemente, os sujeitos negros compreenderam que essa simultaneidade foi percebida pelos hombres blancos, os quais eram os representantes da República del Uruguay, como uma duplicidade que anulava a noção de cidadania plena ao ser negro. A complexidade do que é vivenciado pelo sujeito frente à percepção de um não lugar na sociedade, marcado pela cor de sua pele, que, por seu turno, fundamenta uma ideia de raça, é traduzida aqui na ideia de dupla consciência (Du Bois, 1999: 54), a qual se aproxima da ideia de autoconsciência desenvolvida por Frantz Fanon (2008).

Ter a consciência de se olhar pelos olhos dos outros é um atributo que constitui a identidade social, faz parte da relação dialógica inerente à identidade (Jenkins, 2005). 0 eu-racial é complementado pela perspectiva de Frantz Fanon (2008), esse é o argumento central de seu livro Pele negra, máscaras brancas, que versa sobre a autopercepção dos negros frente à opressão com base na cor da pele, que se traduz na consciência da condição de oprimidos e na busca por emancipação. Por meio dos exemplos, procurei demonstrar aquilo que Thomas Holt (1995) denomina de marcação da raça na história, ou seja, a ideia de raça foi/é um marcador importante que denota diferentes lugares sociais de acordo com a operacionalidade dos seus significados e formas no arranjo social. Acredito que esse olhar pautado em um posicionamento bem delimitado - pessoas negras envolvidas na manutenção do Club Igualdad, e a comunidade negra imaginada ${ }^{28}$ por estas - nos auxilia a observar elementos que comple- 
xificam os próprios sentidos de igualdade na República uruguaia. Estes elementos permitem interpretar a historicidade dos significados de cidadania dentro de um processo que comporta simultaneidades e compreensões da modernidade, a partir do papel político reivindicado pelos negros orientais, e, não obstante, denotam a forma como o racismo incidiu diretamente sobre as possibilidades de existência daquelas pessoas.

A explicitação das evidências da racialização e dos indicativos sobre a natureza do racismo - assentados na violação da liberdade inerente à obrigatoriedade de que todos os homens negros servissem às tropas - reativado na década de 1880 e mantido até a década de 1900, me levam a estender o argumento de Hebe Mattos de que silenciamentos sobre a cor são dificilmente explicados por coincidência. Há evidências de que o contexto influenciou para que não mais se contabilizasse a população com base em raça a partir de 1884 na capital. Enfatizo ainda que, mesmo fora do âmbito político institucional, tais violações de liberdade foram vivenciadas cotidianamente, como se pode observar ao olhar para a sociabilidade de forma mais pontual.

\section{A SOCIABILIDADE RACIALIZADA, OU APENAS MAIS UM CAPÍTULO DA HISTÓRIA DA LIBERDADE NEGRA}

edição de 24 de novembro de 1872 trazia dois informes bem ilustrativos. No primeiro,
foi descrita a primeira reunião "con el objeto de llevar al [...] Legislativo; un hombre de color", ${ }^{29}$ que está de acordo com o previamente disposto aqui. Além de permitir imaginar a reunião em que falaram os então redatores, Marcos Padín e Timoteo Olivera, e o antigo, Andres Seco, é possível perceber como a questão racial era central para o sentido de cidadania que eles estavam pleiteando. Andres Seco propôs que se desse um título à reunião, e o nome sugerido por Olivera foi "Club Raza de Color", o qual intitula a referente matéria. No segundo, foi informado a "los accionistas del Club Igualdad sobre la formación de la biblioteca" , ${ }^{30}$ a qual era uma construção coletiva, visto que José C. Gutierrez, comisionado interino, informava que cada associado havia se comprometido em doar uma obra para o acervo. Em seguida, Gutierrez estendia a solicitação às pessoas apoiadoras do clube e informava que, em janeiro do ano seguinte, 1873 , seria realizada a inauguração do órgão. ${ }^{31}$

Nesse sentido, cabe explicitar que o Club Igualdad tinha caráter político institucional, mantido por associados e fundamentado em uma ideia de raça negra. Não obstante, o jornal aponta para um circuito cultural de clubes e outras sociedades, consideravelmente heterogêneo, também compartilhado por seus membros, bem como por aquelas pessoas que não 
faziam parte no clube, mas das quais o clube se pretendia representante, como as mulheres. As mulheres são referidas especialmente na coluna de crônicas relacionadas aos espaços sociais, sobretudo os bailes, e aos códigos de bom comportamento, e são constantemente apresentadas como um corpo que deve ser controlado.

Encontro ainda alguns anúncios e escritos que apontam para as relações sociais racializadas, vivenciadas além da esfera política institucional, mais precisamente uma sociabilidade negra. As nominações enunciam o caráter racializado das coletividades que compunham a dinâmica da sociedad de color cujos membros tinham a faz de color oscuro; negritos; pichones e pichoncitos, ${ }^{32}$ e, dessa forma, independem de tais pessoas serem adeptas, ou não, do posicionamento do jornal. Entre essas associações encontravam-se a Sociedad Negros Argentinos, ${ }^{33}$ La Raza Africana ${ }^{34}$ e a Sociedad Pobres Negros Orientales. ${ }^{35}$

Goldman (2008: 17) traça a vinculação de membros do Club Igualdad com essas associações, o que corrobora para o entendimento da sociabilidade negra:

Miembros de la Sociedad Pobres Negros Orientales, a su vez, eran socios del Club Igualdad: Manuel Aturaola [...] en 1869 era el Secretario de la Sociedad Pobres Negros Orientales, y el 25 de agosto de 1872 fue socio fundador del Club Igualdad. Lo mismo puede decirse de Manuel Gutiérrez, director de la academia de música de la Sociedad Pobres Negros Orientales y también fundador del Club Igualdad.

O autor informa ainda sobre a circulação e atuação de Marcos Padín e Andrés Seco, associados do Club Igualdad e redatores do jornal La Conservación, os quais se mantiveram "vinculados a todo el movimiento asociativo a partir del año 1872, participaron activamente como autores de textos y de músicas para las comparsas de carnaval". Ambos estavam ligados à comparsa Raza Africana, assim como as salas de naciones africanas ${ }^{36}$ Bayombe e Esclavos de Guinea, e Seco compunha letras para as comparsas Raza Africana e Negros Gramillas. Ambos os redatores sediaram em suas casas, localizadas na zona sul da vieja ciudad, região onde se concentravam os candombes, a administração e redação do jornal La Conservación:

Hacia finales del siglo XIX y principios del XX la mayoría de las sedes de sociedades y comparsas de negros se comienzan a localizar en los barrios Sur y en Palermo - barrios ubicados a pocas cuadras del centro de la ciudad y del centro de decisión política - , dando continuidad a la participación de la población de origen africano, empalmando territorialmente manifestaciones relacionadas con la africanidad que portaban los antiguos miembros de las salas de nación, con las comparsas carnavalescas de negros, fortaleciendo y legitimando a su vez a estos territorios como el lugar en que se localizaban las producciones simbólicas de los africanos y sus descendientes. (Ibidem, 2015: 59). 
Ao que tudo indica, o jornal La Conservación parou de circular em novembro de 1872, ainda antes das eleições; porém, não é equivocado admitir que o Club Igualdad se manteve ativo, ou pelo menos não encerrou oficialmente sua existência, visto que o jornal La Broma de 18 de maio de 1876, representante da imprensa negra argentina, na coluna intitulada "Correspondencia de Montevideo", publicava: "El Club Igualdad está paralizado, no hay trabajos, sufre la crisis por que todos pasamos". ${ }^{37}$ A justificativa encontra correspondência na historiografia, visto que teve início em 1873, e se manteve pelo menos até a década seguinte, uma das crises mais intensas que atingiu o mercado internacional, engendrada na Inglaterra, de onde se espalhou por diferentes países e alcançou o Uruguai (Coggiola, 2009). Não obstante, as lutas em torno da liberdade negra, tanto em termos políticos institucionais quanto de sociabilidade, seguiram sendo tecidas, por meio daquele que já era um legado de homens e mulheres negras.

\section{CONSIDERAÇÕES FINAIS}

esmo que Rodríguez não tenha se elegido e o jornal, aparentemente, tenha deixado
de circular no ano de 1872, as demandas do Club Igualdad permitem entender melhor as visões sobre a cidadania gestadas por um grupo, assim como as evidências da racialização, que, por sua vez, apontavam para as limitações da liberdade e da própria noção de república democrática no Uruguai, uma nação que aboliu a escravidão havia cerca de três décadas, mas que ainda limitava a cidadania com base em elementos raciais, e, desta feita, vivenciava o pós-abolição.

A experiência da criação do Club Igualdad, de caráter político, e do jornal La Conservación, feito seu porta-voz, denota formatos que eram plenamente reconhecidos nas ruas daquela capital e eles eram os veículos dos ares da modernidade que se forjava. Conforme apresentei ao longo deste artigo, foi por meio destas experiências que os homens nelas envolvidos levantaram uma bandeira política institucional com configurações raciais explicitamente colocadas na sociedade civil. Também compartilharam o circuito cultural no qual estavam outras pessoas negras, e expressaram as divergências dentro da própria sociedad de color, especialmente nas matérias acerca dos problemas decorrentes da desunião e sobre a experiência do Club Defensa.

Embora identifique uma identidade compartilhada por estas pessoas - autoidentificadas como raza/sociedad/faz de color - ela sozinha não comporta a explicação acerca dos interesses que mobilizaram a empreitada coletiva do Club Igualdad. Reivindico que ela está aliada 
ao tracejo de uma estratégia de ação específica, que denota a forma como o entendimento acerca da identidade de base racial afetou o modo como essas pessoas julgaram que suas relações sociais deveriam ser estabelecidas tendo em vista os ideais republicanos, sobremaneira a igualdad. A indicação ao Parlamento de um representante que pudesse falar e agir em prol das pessoas de color que, por sua vez, é entendida aqui como uma dimensão de cidadania forjada, simultaneamente política (inclusiva), cultural e social. Ao entendimento desta dimensão se soma o caráter da racialização historicamente determinada, que excluía parte da população negra do acesso à cidadania política desde a abolição da escravidão, fundamentada nos contratos de peonagem, no recrutamento forçado e no gênero, ao mesmo tempo em que incluía pessoas brancas.

Todos esses elementos apontam para as experiências em tempos de liberdade, ainda pautadas por noções de raça, bem como para a heterogeneidade de entendimentos a partir da (auto)identificação com base em uma ideia de raça, e compuseram o sentido do projeto levado a cabo pelas pessoas que fundaram o referido clube. Neste projeto, não se fazia necessário negar a pertença racial e tampouco relegar sua representação a outro grupo, como os hombres blancos e/ou o Partido Colorado, visto que tais elementos eram simultâneos e mesmo duplos - mas não ambíguos -, como explicitado anteriormente. Estes elementos dão conta da complexidade do processo histórico vivenciado nos idos do ano de 1872, em Montevidéu, em que uma identidade negra compartilhada, pela qual se definiam os contornos da comunidade imaginada, aliada aos interesses em comum, resultou na construção de um projeto coletivo, que, por sua vez, estava inserido na comunidade, mas não era a sua expressão em termos de homogeneidade ou totalidade. Este processo dá corpo à assertiva da filósofa Angela Davis (2009: 119) acerca das comunidades, cujas delimitações são conferidas pelos projetos políticos compartilhados.

O Club Igualdad foi a expressão que forneceu alguns dos elementos para a análise dos processos de liberdade negra no Uruguai. A trajetória uruguaia foi marcada por três momentos. 0 primeiro foi culminado pelas leis de emancipação gradual, que datam da segunda década do século XIX. 0 segundo foi marcado pelas leis de abolição, promulgadas em 1842 e 1846, que limitaram a cidadania negra por meio da adoção dos contratos de peonagem e recrutamento forçado. A partir destas leis, o significado da raça, atribuído pelo Estado Oriental, foi aliado à restrição de cidadania. De posse desse entendimento, já se afastando mais de duas décadas das leis de abolição e cientes das retóricas democráticas, temos o terceiro momento, em que a cidadania foi reivindicada publicamente por um coletivo de homens negros, não como algo a ser conquistado, mas como algo a ser assegurado. Cidadania entendida 
como um direito de acordo com os ditames do governo republicano que regia o Estado Oriental e, em parte, uma livre interpretação das leis de abolição da escravidão, que, por sua vez, marca as demandas observadas no ano de 1872, como o exemplo do Club Igualdade permite acompanhar.

Fosse pelo caráter político de fazer parte das determinações da nação por meio de um representante, ou fosse pelo seu caráter social de constituir e manter espaços de lazer próprios para as pessoas negras e, até mesmo da divulgação da existência desses espaços nos países vizinhos, as pessoas que deram corpo a estas múltiplas experiências estavam também fazendo a história da jovem República uruguaia em tempos de pós-abolição. Desta feita, a análise com o foco aqui apresentado permite que, na condição de historiadoras e historiadores, possamos fazer um exercício de destacar outros lugares e corpos que também foram atravessados pela perversidade da racialização, ou seja, pelo que hoje denominamos de racismo.

\section{Notas}

1 Os 17 exemplares do La Conservación foram publicados entre 4 de agosto de 1872 e 24 de novembro de 1872, e estão disponíveis no site da Biblioteca Nacional del Uruguay (http://bibliotecadigital.bibna.gub. uy:8080/jspui/handle/123456789/25840).

2 "Guerra Grande é a denominação que a historiografia uruguaia dá ao conflito entre os partidos Colorado e Blanco. Profundamente aliados aos unitários argentinos, os colorados, liderados por Fructuoso Rivera, tornaram-se alvo do presidente vizinho Juan Manuel Rosas, que, por sua vez, era aliado do principal líder dos blancos, Manuel Oribe. Por mais que seja considerada uma guerra civil, este conflito extrapolava as fronteiras, coexistindo na Argentina e apenas tendo sido encerrado graças à interferência militar do Império do Brasil" (Menegat, 2015: 12-13).

3 Refiro-me à Ley n² 242, Esclavitud (I) (República Oriental del Uruguay, 1842).

4 Ao reportar questões semelhantes no Brasil (Cunha; Gomes, 2007).

5 A Constituição de 1830 (República Oriental del Uruguay, 1830) assegurava a cidadania a todos os cidadãos maiores de 20 anos, fossem eles naturais, homens livres nascidos no solo oriental, ou legais, cujas exigências estavam ali descritas. A cidadania poderia ser suspensa em casos previstos, dos quais destaco a inaptidão física ou moral, bem como "por la condición de sirviente a sueldo, peón jornalero, simples soldado de línea, notoriamente vago o legalmente procesado en causa criminal, de que pueda resultar pena corporal o infamante".

6 Para uma análise do trabalho das mulheres escravizadas e na modalidade de contratos, ver Iglesias, Karla Chagas. De escravas, "contratadas" e criadas: os relatos de Cecília sobre o trabalho na fronteira uruguaio-brasileira. In: Grinberg, Keila. As fronteiras da escravidão e da liberdade no sul da América. Rio de Janeiro: Faperj, 2013. p. 199-211.

7 ver nota 3. 


\section{Idem.}

9 A assembleia regulamentou o fim do tráfico de escravos e decretou que negros que adentrassem o território seriam considerados livres. Porém, na prática instituiu-se a tutela, pela autoridade pública, para os menores de 25 anos até completar essa idade, e para os maiores pelo prazo de três anos (Flores, 2014).

10 A ideia de raça denota uma hierarquização, cujos significados são forjados em um processo e contexto social e histórico determinados (Silva, 2017).

11 A primeira lei ficou conhecida como "Ley de la Abolición"; a segunda, como "Ley de la Abolición Definitiva", e ambas trouxeram a questão da indenização. A primeira previu a indenização em caso de descontentamento dos senhores, o que de fato não se deu de pronto, e a segunda informava que os valores dos escravos eram uma dívida da nação, logo, os donos seriam recompensados de acordo com valores estipulados pelas normas da lei.

12 Semelhante ao que o historiador Sidney Chalhoub apontou para o Rio de Janeiro nas últimas décadas do século XIX, quando o Brasil também discutia a abolição. Ver: Chalhoub, Sidney. Visões da liberdade: uma história das últimas décadas da escravidão na Corte. São Paulo: Companhia das Letras, 2011.

13 Ano que marca a paz social, com o fim de conflitos que haviam se estendido por quatro décadas, e que assinalava aos negros uruguaios a possibilidade de uma mudança política significativa que fizesse valer os ideais liberais, entre os quais a igualdade (Goldman, 2016).

14 La Conservación, 4 de agosto de 1872, p. 1. As páginas do jornal não estão numeradas, a numeração aqui presente faz referência à capa (1), ao verso da capa (2), ao verso da contracapa (3) e à contracapa (4).

15 La Conservación, 15 de setembro de 1872, p. 1.

16 Composta pelas Câmaras de Representantes e de Senadores, responsáveis por eleger o presidente da República em março de 1873. (República Oriental del Uruguay, 1830).

17 A definição foi escrita provavelmente no ano de 1834. Jacinto Ventura de Molina nasceu em Rio Grande de São Pedro, na fronteira entre os impérios espanhol e português, no ano de 1766, e foi tenente na Compañía de Morenos Libres de 1807, formado em Direito e secretário da Cofradía de San Benit. (Acree Jr.; Borucki, 2008: 129).

18 La Conservación, 29 de setembro de 1872, p. 1.

19 Idem.

20 Idem.

21 Ibidem, 22 de setembro de 1872, p. 1.

22 Os autores analisam o que estava além da escravidão nas sociedades pós-emancipação, atentando para como as reflexões sobre inclusão e exclusão foram direcionadas e reconduzidas quando a escravidão estava sucumbindo.

23 La Conservación, 6 de novembro de 1872, p. 2.

24 Fundado em 1872, de caráter político. Com base em matéria publicada no periódico montevideano Ferro Carril, Gustavo Goldman (2016: 183) afirma que "El Club Defensa se presentaba a la opinión pública como una 'asociación política de todos los ciudadanos de color que simpatizan con las elevadas y patrióticas ideas del Partido Colorado'". 
25 La Conservación, 27 de outubro de 1872, p. 1.

26 o governo que se estabeleceu em Montevidéu - a Troya - recebeu o nome Gobierno de la Defensa, sendo que o clube referido, também de negros, adotava a nominação "Defensa", o que podia denotar um referencial de nacionalidade.

27 Em geral, a escrita é direcionada a um sujeito negro universal, e em alguns casos refere-se às mulheres da raça, morochas e pichonas.

28 Concordo com a ideia de comunidade imaginada desenvolvida por Benedict Anderson. 0 autor desenvolve tal concepção para pensar a nação, a qual é entendida como "uma comunidade política imaginada - e imaginada como sendo intrinsecamente limitada e, ao mesmo tempo, soberana. Ela é imaginada, porque mesmo os membros da mais minúscula das nações jamais conhecerão, encontrarão ou sequer ouvirão falar da maioria de seus companheiros, embora todos tenham em mente a imagem viva da comunhão entre eles" (Anderson, 2008: 32).

29 La Conservación, 24 de novembro de 1872, p. 2.

30 Ibidem, p. 3.

31 Idem.

32 Terminologias presentes no jornal e que fazem menção a indivíduos tidos como da mesma sociedade cujo jornal se arroga o título de representante - órgano de la sociedad de color. Apenas pichón aparece generificado, por meio da expressão pichona.

33 La Conservación, 13 de outubro de 1872, p. 3. Gustavo Goldman (2015: 58) destaca que essa associação foi provavelmente fundada no ano de 1872, e tinha uma comparsa atuante no Carnaval. Comparsa é um grupo carnavalesco, com instrumentos de sopro e cordas, e havia comparsas de negros. Surgiu como uma extensão das Salas de Nación, e tinha forte vínculo com o candombe, manifestação de carnaval uruguaio.

34 La Conservación, 4 de agosto de 1872, p. 3. Comparsa criada em 1867 (a única sociedade do período que evoca a África). (Andrews, 2011: 67)

35 La Conservación, 18 de agosto de 1872, p. 2. A comparsa foi criada em 1869. Ao analisar o regulamento dessa associação, Andrews (2011: 76) destaca que "se planteó como finalidad la creación de una academia de música y la participación en el carnaval".

36 Sociedades de africanos, organizadas por grupos de origem étnica que remontam ao período colonial.

37 La Broma, 18 de maio de 1876, p. 2.0 jornal La Broma foi editado em Buenos Aires entre $1^{\circ}$ de maio de 1876 e 28 de dezembro de 1882 (Cirio, 2009).

\section{REFERÊNCIAS BIBLIOGRÁFICAS}

ACREE JR., William G.; BORUCKI, Alex (ed.). Jacinto Ventura de Molina y los caminos de la escritura negra en el Río de la Plata. Montevidéu: Librería Linardi y Risso, 2008.

ANDERSON, Benedict. Comunidades imaginadas. São Paulo: Companhia das Letras, 2008. 
ANDREWS, George Reid. América afro-latina - 1800-2000. São Carlos: EdUFSCar, 2007. Negros en la nación blanca: historia de los afro-uruguayos. Montevidéu: Librería Linardi y Risso, 2011.

AROCENA, Felipe; Aguiar, Sebastián. Multiculturalismo en Uruguay. ensayo y entrevistas a once comunidades culturales. Montevidéu: Ediciones Trilce, 2007.

BORUCKI, Alex; CHAGAS, Karla; STALLA, Natalia. Esclavitud y trabajo. Un estudio sobre los afrodescendientes en la frontera uruguaya (1835-1855). Montevidéu: Mastergraf, 2009.

BURKE, Peter. A história social dos clubes. Folha de S. Paulo, São Paulo, 24 fev. de 2002.

CARDOSO, Lourenço. O branco ante a rebeldia do desejo: um estudo sobre a branquitude no Brasil. 2014. Tese (Doutorado em Ciências Sociais) - Universidade Estadual Paulista Júlio de Mesquita Filho, Araraquara. 2014..

CIRIO, Norberto Pablo. Tinta negra en el gris del ayer: los afroporteños a través de sus periódicos entre 1873 y 1882. Buenos Aires: Teseo, 2009. p. 153-228.

COGGIOLA, Osvaldo. As grandes depressões (1873-1896 e 1929-1939): fundamentos econômicos, consequências geopolíticas e lições para o presente. São Paulo: Alameda, 2009.

COOPER, Frederick; HOLT, Thomas C.; SCOTT, Rebecca J. Além da escravidão: investigações sobre raça, trabaIho e cidadania em sociedades pós-emancipação. Rio de Janeiro: Civilização Brasileira, 2005.

CUNHA, Olívia Gomes da; GOMES, Flávio dos Santos (org.). Quase-cidadão: histórias e antropologias da pós-emancipação no Brasil. Rio de Janeiro: Editora FGV, 2007.

DAVIS, Angela Y. A democracia da abolição - para além do Império, das prisões e da tortura. Rio de Janeiro: Difel, 2009.

W. E. B. As almas da gente negra. Rio de Janeiro: Lacerda, 1999.

FANON, Frantz. Pele negra, máscaras brancas. Salvador: EDUFBA, 2008.

FLORES, Mariana Flores da Cunha Thompson. Crimes de fronteira: a criminalidade na fronteira meridional do Brasil (1845-1889). Porto Alegre: EDIPUCRS, 2014. Coleção e-book ANPUH-RS.

GILROY, Paul. O Atlântico Negro: modernidade e dupla consciência. São Paulo: Editora 34; Rio de Janeiro: Ucam, 2001.

GOLDMAN, Gustavo. Lucamba. Herencia africana en el tango. 1870-1890. Montevidéu: Perro Andaluz Ediciones, 2008.

. Negros modernos: música, territorio y asociacionismo al sur de la ciudad de Montevideo a fines del siglo XIX. Boletín de Mísica, n. 41, p. 49-65, 2015.

. Los otros ciudadanos: Asociacionismo, prensa y política de los negros montevideanos a fines del siglo XIX. Claves, Revista de Historia, n. 2, p. 175-198, jan.-jun. 2016.

HOLT, Thomas. C. Marking: Race, Race-Making, and the Writing of History. The American Historical Review, v. 100, n.1, p. 1-20, 1995.

JENKINS, Richard. Social Identity. Nova York: Routledge, 2005. 
MATTOS, Hebe Maria. Das cores do silêncio - Os significados da liberdade no Sudeste escravista — Brasil, século XIX. Campinas (SP): Editora da UNICAMP, 2015.

MENEGAT, Carla. "Transportando fortunas para povoar deserta e inculta campanha": atuação política e negócios dos brasileiros no norte do Estado Oriental do Uruguai. (1845- 1835). 2015. Tese (Doutorado em História) - Universidade Federal do Rio Grande do Sul, Porto Alegre. 2015.

REPÚBLICA ORIENTAL DEL URUGUAY. Ley n² 242. Esclavitud (I), de 12 de deciembre de 1842. Disponível em http://archivo.presidencia.gub.uy/_Web/ddhh/LEY242.htm.

Constitución de la República. Montevidéu, 28 de julio de 1830. Disponível em https://legislativo. parlamento.gub.uy/temporales/2172689.HTML\#art57

SILVA, Fernanda Oliveira da. As lutas políticas nos clubes negros: culturas negras, racialização e cidadania na fronteira Brasil-Uruguai no pós-abolição (1870-1960). 2017. Tese (Doutorado em História) - Universidade Federal do Rio Grande do Sul, Porto Alegre. 2017. 